\title{
Sea surface temperature east of Australia: A predictor of tropical cyclone frequency over the western North Pacific?
}

\author{
ZHOU BoTao ${ }^{1,2^{*}} \&$ CUI Xuan ${ }^{3}$ \\ ${ }^{1}$ National Climate Center, China Meteorological Administration, Beijing 100081, China; \\ ${ }^{2}$ Nansen-Zhu International Research Center, Institute of Atmospheric Physics, Chinese Academy of Sciences, Beijing 100029, China; \\ ${ }^{3}$ National Meteorological Center, China Meteorological Administration, Beijing 100081, China
}

Received July 5, 2010; accepted August 16, 2010; published online October 26, 2010

\begin{abstract}
The relationship between sea surface temperature (SST) east of Australia and tropical cyclone frequency over the western North Pacific (WNPTCF) is analyzed by use of observation data. The WNPTCF from June to October is correlated negatively to spring SST east of Australia. When the spring SST is in the positive phase, a cyclonic circulation anomaly in the upper troposphere and an anticyclonic circulation anomaly in the lower troposphere prevail over the western North Pacific from June to October, concurrent with an anomalous atmospheric subsidence and an enlarged vertical zonal wind shear. These conditions are unfavorable for tropical cyclone genesis, and thus WNPTCF decreases. The negative phase of the spring SST east of Australia leads to more tropical cyclones over the western North Pacific. The spring SST east of Australia may give rise to simultaneous change in tropical atmospheric circulation via the teleconnection wave train, and then subsequently affect atmospheric circulation variation over the western North Pacific.
\end{abstract}

western North Pacific, tropical cyclone frequency, sea surface temperature, atmospheric circulation, teleconnection

Citation: Zhou B T, Cui X. Sea surface temperature east of Australia: A predictor of tropical cyclone frequency over the western North Pacific? Chinese Sci Bull, 2011, 56: 196-201, doi: 10.1007/s11434-010-4157-5

Tropical cyclones (TCs) are a strongly synoptic phenomenon generated over tropical oceans. Their occurrence often engenders rainstorms and storm surges, which in many countries results in economic loss and human deaths. Because TCs occur most frequently over the western North Pacific (WNP), the interannual variability in and predictability of TC activity in this region is of prime interest. Research on this issue can improve understanding the mechanisms of TC variation and provide a scientific basis for short-term prediction, thereby enhancing defense ability against such disastrous weather and reducing losses.

Many studies have been conducted to determine the genesis, evolution, and the relevant climate characteristic of TCs over the WNP [1-5]. Variations in TC activity are determined mainly by the large-scale atmospheric circulation system and the ocean temperature condition. The monsoon

*Corresponding author (email: zhoubt@cma.gov.cn) trough, stratospheric quasi-biennial oscillation, MaddenJulian oscillation and Rossby-gravity wave all can exert significant impacts on TC activity over the WNP [2,6-10]. In recent years, several studies have further investigated the influence of atmospheric modes on tropical cyclone frequency over the western North Pacific (WNPTCF). Wang et al. $[11,12]$ showed that WNP typhoon number during June to September is correlated negatively to the Antarctic oscillation and positively to the North Pacific oscillation. Zhou et al. [13] and Cui et al. [14] found that a strong (weak) Asian-Pacific oscillation in summer is advantageous (disadvantageous) for TC genesis, and thus TC frequency increases (decreases) over the WNP.

Many studies have highlighted that El Niño-Southern Oscillation (ENSO) can significantly affect TC frequency, intensity and location over the WNP by influencing ocean temperature, through changes in the magnitude of the vertical zonal wind shear, Walker circulation, monsoon trough 
etc. [15-21]. Additionally, thermal states in the warm pool also have effects on TC activity over the WNP. During the warm state there are fewer typhoons and tropical storms tend to form in the northwest of the WNP and move westward. During the cold state typhoons appear in the southeast WNP [22,23].

Because China suffers from TCs over the WNP, it is essential to carry out predictions of TC activity in this region. To perform better predictions, antecedent signals have been widely sought. For example, Zhou and Cui [24,25] examined the relationship between the spring Hadley circulation and summer WNPTCF. Their results showed that a strong (weak) phase of the spring Hadley circulation corresponded to lower (higher) WNPTCF. Chan et al. [26,27] analyzed WNPTCF variability in the years before, when and after El Niño or La Niña happened, and applied ENSO as an important seasonal indicator of TC activity over the WNP. Fan [28] proposed that large sea ice cover in the North Pacific during winter and spring tends to decrease WNPTCF, and used it as a new predictor to establish a forecast model [29,30].

Interannual variability in TC activity over the WNP is complicated, and identifying other crucial factors is important for characterizing TC variability and predictability. It has been noted that atmospheric circulations in the Southern Hemisphere are tightly connected to the typhoon activity [31-33]. If SST change directly affects atmospheric circulations, is Southern Hemispheric SST linked to TC activity over the WNP? If so, can it be employed as a potential indicator in predicting TCs over the WNP? Since previous studies focused mainly on the influence of Northern Hemispheric SST and paid less attention to the influence of Southern Hemispheric SST, the present study addresses the linkage between Southern Hemispheric SST and WNPTCF.

\section{Data}

The datasets used were (1) NCEP/NCAR reanalysis data [34] with horizontal resolution of $2.5^{\circ} \times 2.5^{\circ}$, (2) NOAA SST data [35] with horizontal resolution of $2^{\circ} \times 2^{\circ}$, and (3) TC record provided by the Joint Typhoon Warning Center (JTWC) [36]. Generally, TCs are classified into tropical depressions, tropical storms and typhoons, depending on their maximum sustained wind speeds. In this study, TCs refer only to tropical storms and typhoons. Time series for the analysis covers the period 1971-2005.

\section{Results}

Figure 1 shows correlations between the June-October (JJASO) mean WNPTCF and the spring (MAM) and JJASO SST. There were significant negative correlations in the region east of Australia, with the maximum value above
-0.5 (Figure 1(a)). Such an out-of-phase relationship also existed in JJASO (Figure 1(b)), but the significance area was smaller than that in Figure 1(a). This suggests that the SST east of Australia in spring has larger effects than its counterpart in JJASO on the JJASO WNPTCF. To assess the possible influence of the linear trend, we further calculated correlations between JJASO WNPTCF and the spring and JJASO SST after filtering. Interestingly, the correlation pattern after detrending (Figure not shown) conforms to that presented in Figure 1. Other research [15-21] has shown that ENSO is linked closely to TC activity over the WNP. To identify the possible influence of ENSO, we also computed SST-WNPTCF correlations after removing the ENSO signal. The correlation pattern resembles that before removing ENSO signal.

To describe temporal variation in the SST east of Australia, we defined an index (EASST) as the regional mean SST within the significance area shown in Figure 1(a). The time series of the spring EASST and JJASO WNPTCF is shown in Figure 2(a). The out-of-phase relationship between them is very prominent, with correlation coefficients of -0.57 and -0.55 , respectively, for the non-detrended and detrended results, both significant at the $99.9 \%$ level. The negative correlation is remarkable after the late 1980s compared with earlier, reflecting an interdecadal change. This phenomenon may be related to the interdecadal climate transition occurring in the late 1980s [37-39]. The ENSO event also exhibits interdecadal change during the 20th century [40]. However, detailed mechanisms need to be studied further. Figure 2(b) shows correlations between JJASO WNPTCF and the EASST in each month. The
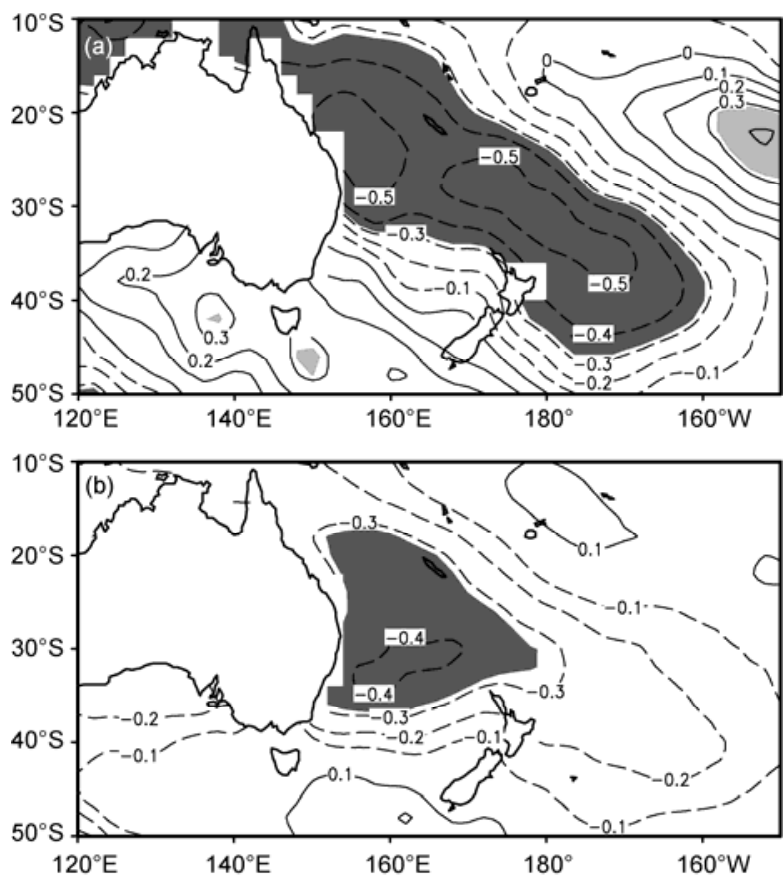

Figure 1 Correlations between JJASO WNPTCF and MAM (a) and JJASO (b) SST. Regions above the 95\% significance level are shaded. 

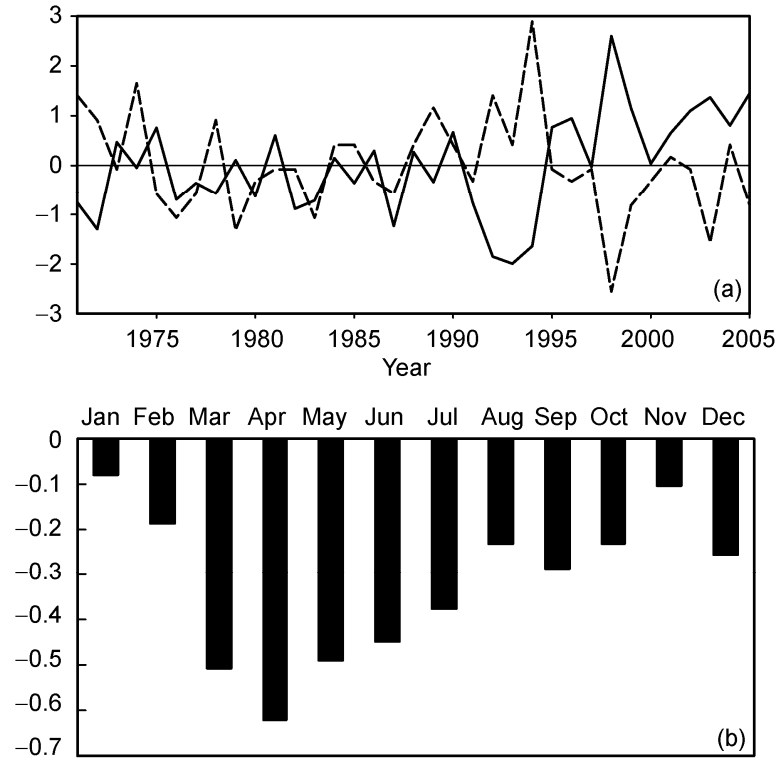

Figure 2 (a) Time series of the normalized MAM EASST (solid line) and JJASO WNPTCF (dashed line). (b) Correlations between JJASO WNPTCF and the monthly SST.

JJASO WNPTCF is negatively correlated to the preceding and simultaneous EASST. Nevertheless, the negative correlations between JJASO WNPTCF and the EASST in March, April and May are the largest, whereas its correlations with the EASST in January and February are not pronounced (not significant at the $95 \%$ level).

These results show that the SST anomaly east of Australia in spring can exert significant effects on WNPTCF change. If the SST east of Australia is above (below) normal in spring, the WNPTCF will decrease (increase) in JJASO. To reveal the possible mechanism responsible for their linkage, we analyzed the atmospheric circulations associated with change in spring SST east of Australia using linear regression. Regression coefficients can be obtained by applying the least square method to the equation $y(t)=$ $a x(t)+b$, where $y(t)$ is the physical variable, $t$ is time, $x(t)$ is the time series of the normalized index (EASST or WNPTCF), $a$ is the regression coefficient and $b$ is a constant. The pattern of the regression coefficient $a$ denotes change in variable $y$ (horizontal wind and vertical velocity) corresponding to the $x$ change by one standard deviation. The significance of the regression coefficient was assessed by the Student's $t$-test [41].

Figure 3(a) and (b) depict regressions of JJASO horizontal winds at 850 and $200 \mathrm{hPa}$ against the spring EASST, respectively. In association with warmer SST east of Australia in spring, an anomalous easterly prevails in the lower troposphere of the tropical western Pacific during JJASO, indicative of a weakened monsoon trough. Concurrently, two anomalous anticyclonic circulations are located on both sides of the equator (Figure 3(a)). In the upper troposphere, the westerly anomaly is predominant over the tropical western Pacific, concomitant with anomalous cyclonic circula- tions on either side (Figure 3(b)). Such a pattern corresponds to the atmospheric background for fewer TCs, which can be shown by the regressions of the $850 \mathrm{hPa}$ and $200 \mathrm{hPa}$ winds against JJASO WNPTCF. As shown in Figure 3(c) and (d), the atmospheric circulation system related to more (less) WNPTCF comprises the anomalous cyclonic (anticyclonic) circulation over the WNP and anomalous westerly (easterly) over the tropical Pacific in the lower troposphere as well as the anticyclonic (cyclonic) circulation anomaly over the WNP and easterly (westerly) anomaly over the tropical Pacific in the upper troposphere.

Changes in high- and low-level winds may cause atmospheric vertical motion to be abnormal. Figure 4(a) shows that positive values appear in large areas east of $140^{\circ} \mathrm{E}$, which indicates that corresponding to anomalous low-level anticyclonic circulation and high-level cyclonic circulation in Figure 3(a) and (b), anomalous subsidence dominates the WNP in JJASO. The regression pattern of the vertical velocity along $0^{\circ}-30^{\circ} \mathrm{N}$ upon JJASO WNPTCF displayed in Figure 4(b) is generally the converse of that in Figure 4(a). A large negative anomaly emerges the east of $140^{\circ} \mathrm{E}$, implying that anomalous ascending (descending) over the WNP corresponds to more (less) WNPTCF. Therefore, Figure 4 well illustrates that anomalous downward (upward) motion over the WNP in JJASO is related to the warmer (colder) spring SST east of Australia and is unfavorable (favorable) for TC genesis in this region. This further confirms the out-of phase relationship between spring EASST and JJASO WNPTCF.

Changes in high- and low-level winds can also result in variation in the magnitude of the vertical zonal wind shear, which is a crucial environmental condition for TC genesis and development. Studies $[1,11,12,24,42,43]$ have demonstrated the inverse relationship between TC frequency and the vertical zonal wind shear. Low vertical zonal wind shear benefits TC genesis and development. Conversely, high vertical zonal wind shear does not favor TC genesis and development. Such a linkage can be clearly detected in the regression of vertical zonal wind shear against JJASO WNPTCF (Figure 5(b)), which shows negative coefficients in the major TC genesis region. Figure 5(a) shows regressions of the JJASO vertical zonal wind shear against the spring EASST. The pattern of positive anomalies in the major TC genesis region over the WNP is almost opposite to that in Figure 5(b). Therefore, vertical zonal wind shear is intensified during JJASO in association with the positive phase of spring SST east of Australia, disadvantageous for TC genesis over the WNP, and vice verse.

To sum up, when spring SST east of Australia is warmer (colder) than normal, anomalous low-level anticyclonic (cyclonic) and high-level cyclonic (anticyclonic) circulations occur over the WNP during the following JJASO. Correspondingly, the airflow descends (ascends) and the vertical zonal wind shear strengthens (weakens). These conditions are unfavorable (favorable) for TC genesis and 

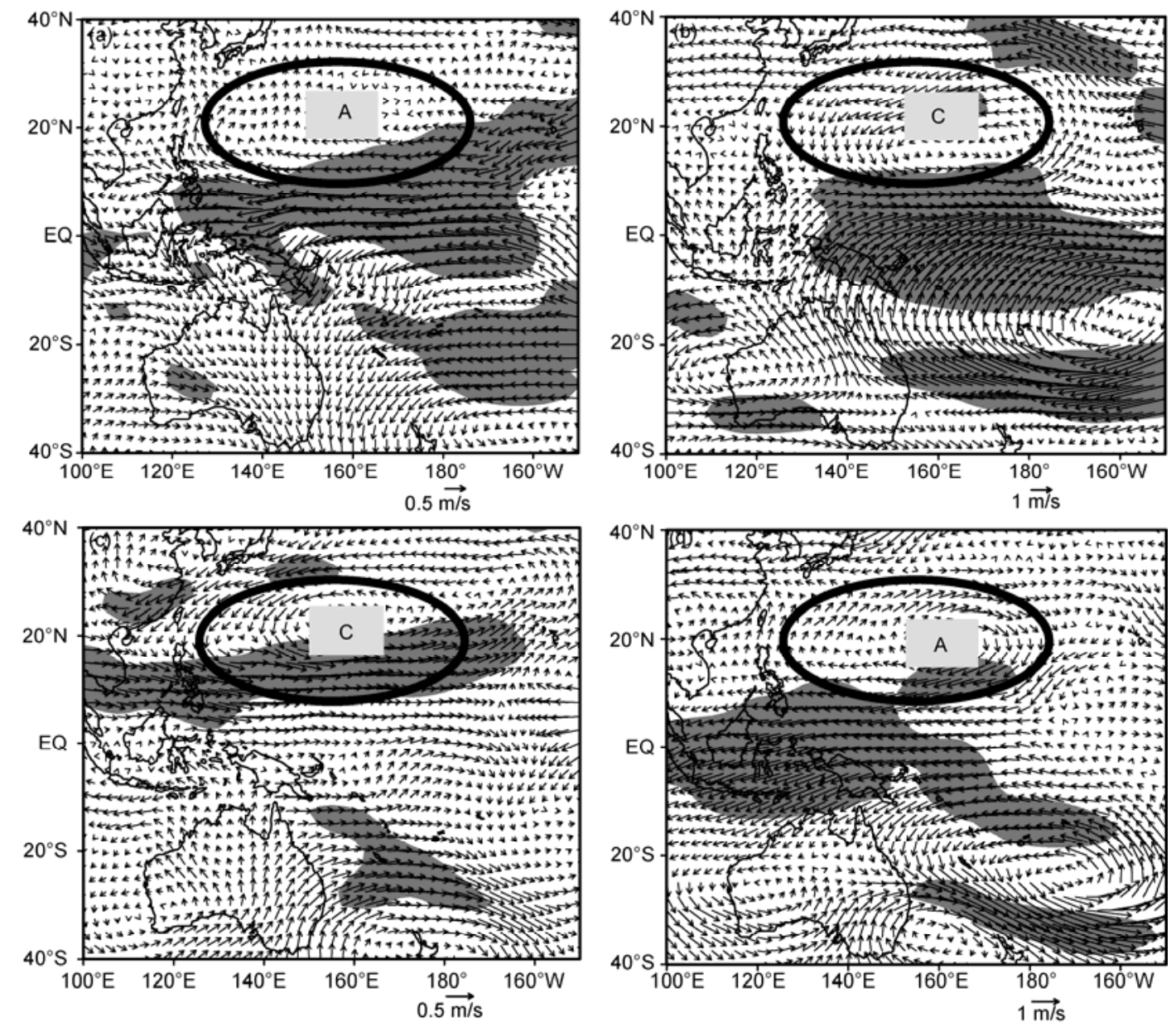

Figure 3 Regressions of JJASO winds at $850 \mathrm{hPa}\left(\mathrm{UV}_{850}\right)$ and $200 \mathrm{hPa}\left(\mathrm{UV}_{200}\right)$ respectively against MAM EASST and JJASO WNPTCF. (a) $\mathrm{UV}_{850}$-EASST; (b) UV $\mathrm{U}_{200}$-EASST; (c) $\mathrm{UV}_{850}$-WNPTCF; (d) UV $\mathrm{UV0}_{200}$-WNPTCF. Regions above the 95\% significance level are shaded. A and C in the figures denote anticyclonic circulation and cyclonic circulation, respectively.
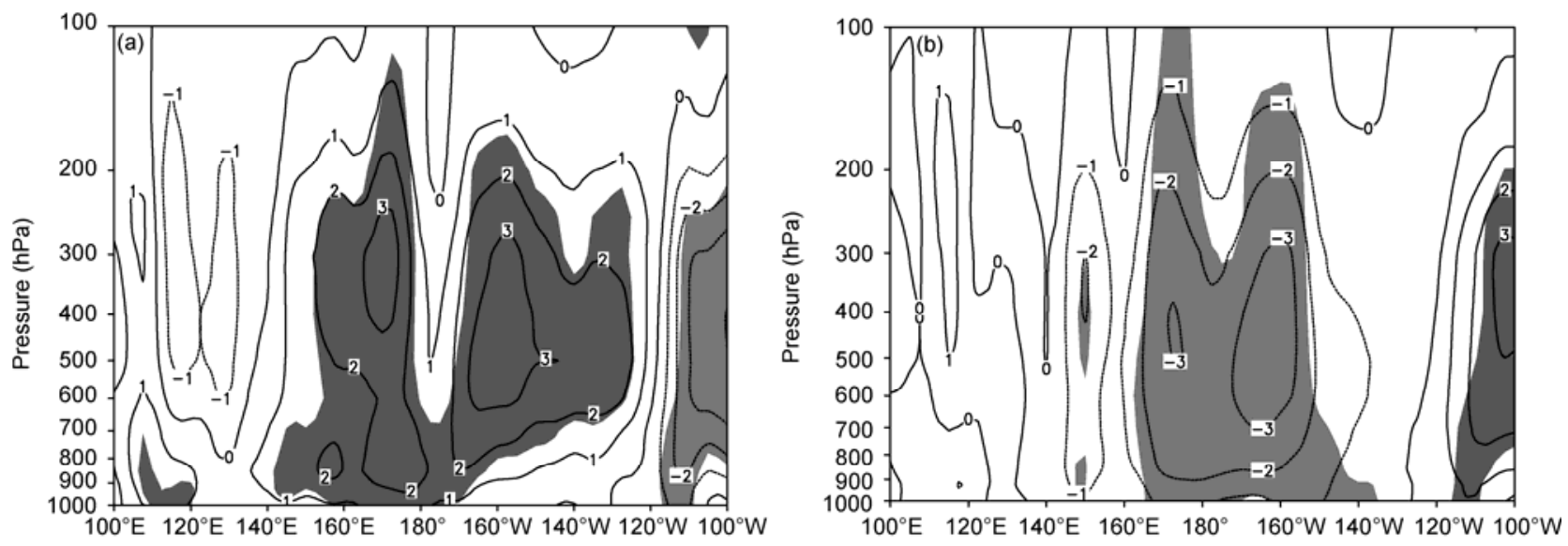

Figure 4 Cross-section of regressions of JJASO vertical velocity (in $10^{-3} \mathrm{~Pa} \mathrm{~s}^{-1}$ ) along $0^{\circ}-30^{\circ} \mathrm{N}$ against MAM EASST (a) and JJASO WNPTCF (b). Regions above the $95 \%$ significance level are shaded.

hence the WNPTCF decreases (increases).

How does the spring SST east of Australia affect atmospheric circulation over the WNP? As is known, atmospheric circulation change over the tropical Pacific has a good seasonal persistence $[28,44]$. This strong seasonal persistence may play an important role in their linkage. To further test our speculation, the regression of $200 \mathrm{hPa}$ winds against the EASST in spring is plotted in Figure 6. Anomalous anticyclonic circulation, cyclonic circulation and cyclonic circulation can be observed from south to north in the Pacific. The 

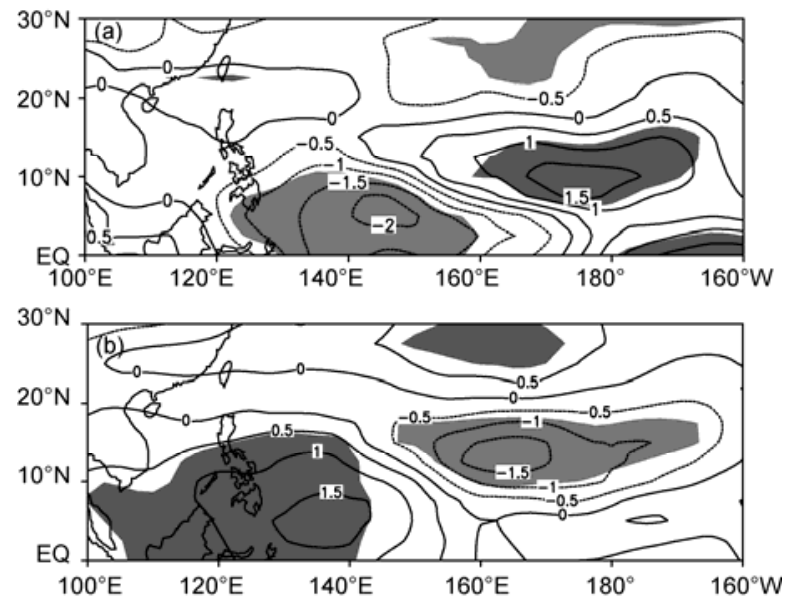

Figure 5 Regressions of JJASO vertical zonal wind shear (unit: $\mathrm{m} / \mathrm{s}$ ) against MAM EASST (a) and JJASO WNPTCF (b). Regions above the $95 \%$ significance level are shaded.

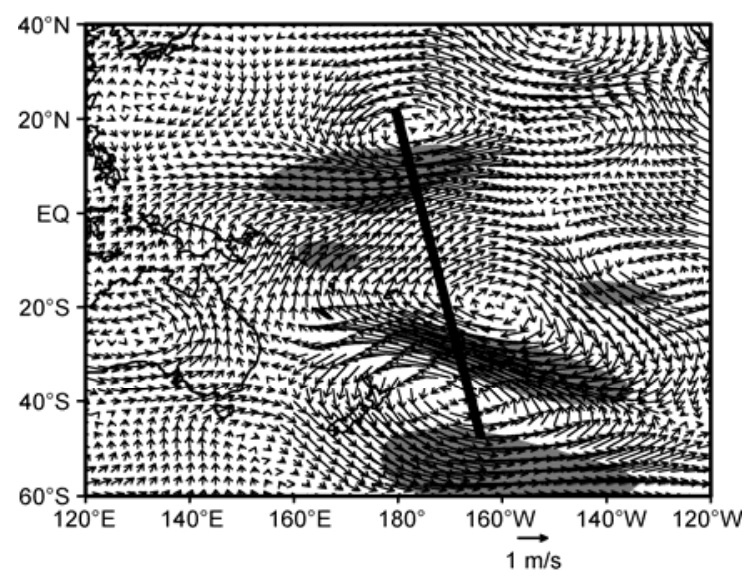

Figure 6 Regressions of the horizontal wind (unit: $\mathrm{m} / \mathrm{s}$ ) at $200 \mathrm{hPa}$ against EASST in spring. Regions above the $95 \%$ significance level are shaded.

tropical Pacific is occupied by an anomalous westerly. Therefore, SST east of Australia can induce the tropical atmospheric circulation anomaly in spring via the meridional teleconnection. Due to the seasonal persistence of the tropical atmospheric circulation, such an anomaly may last from MAM to JJASO and subsequently affect TC activity over the WNP. Seen in Figure 7, the upper-tropospheric zonal wind anomaly over the tropical Pacific, which results from change in spring SST east of Australia, can persist from spring until October.

\section{Conclusions}

We addressed the influence of spring SST east of Australia on WNPTCF change in JJASO. The JJASO WNPTCF is correlated negatively to spring SST east of Australia. The correlation coefficients between MAM EASST and JJASO WNPTCF were -0.57 and -0.55 respectively for the nondetrended and detrended time series in the period 1971-

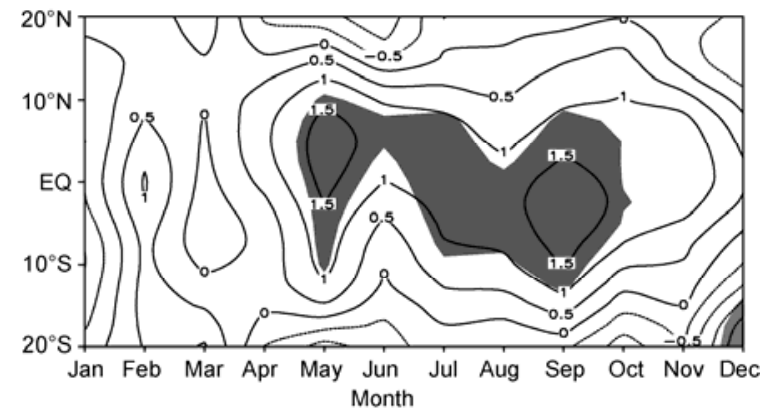

Figure 7 Regressions of monthly zonal wind (unit: m/s) at $200 \mathrm{hPa}$ against MAM EASST. Regions above the 95\% significance level are shaded.

2005, and both were significant at the $99.9 \%$ level. It is thus suggested that spring SST east of Australia may be a potential indicator affecting WNPTCF. If the SST east of Australia is in the positive (negative) phase in spring, fewer (more) TCs will occur over the WNP in the following JJASO.

We identified a possible mechanism responsible for the effect of spring SST east of Australia on JJASO WNPTCF. A positive phase of spring SST east of Australia is followed by a cyclonic circulation anomaly in the upper troposphere, and an anticyclonic circulation anomaly in the lower troposphere over the WNP in JJASO. Consequently, the airflow subsides to constrain convective activity. Meanwhile, the vertical zonal wind shear increases in the major TC genesis region. These conditions do not favor TC genesis and development, and thus the WNPTCF is decreased. The opposite situation favoring TC genesis over the WNP corresponds to the negative phase of spring SST east of Australia. Further analysis indicates that spring SST east of Australia can simultaneously change the tropical circulation via atmospheric teleconnection. Due to the strong seasonal persistence of the tropical circulation, the tropical circulation anomaly can persist from spring to JJASO, and then potentially modulate the atmospheric circulations associated with WNPTCF

This candidate mechanism is a preliminary explanation. Other processes may also act in their linkage. Because airsea interactions are complex, more in-depth analyses are needed to clarify the detailed physical processes and dynamic mechanisms of the influence of spring SST east of Australia on the WNPTCF. Our statistical conclusions also need to be validated by numerical models. So, our future research will attempt to conduct rational sensitivity experiments with state-of-the-art climate models.

This work was supported by the National Natural Science Foundation of China (40805029), the National Basic Research Program of China (2009CB421407) and the Knowledge Innovation Program of the Chinese Academy of Sciences (IAP09302).

1 Gray W M. Global view of the origin of tropical disturbances and storms. Mon Weather Rev, 1968, 96: 669-700

2 Ding Y H, Reiter E R. Large-scale circulation influencing the typhoon formation over the West Pacific (in Chinese). Acta Oceanol 
Sin, 1983, 5: 561-574

3 Chia H H, Ropelewski C F. The interannual variability in the genesis location of tropical cyclones in the Northwest Pacific. J Clim, 2002, 15: 2934-2944

4 Yuan J N, Wang D X, Liu C X, et al. The characteristic differences of tropical cyclones forming over the western North Pacific and the South China Sea. Acta Oceanol Sin, 2007, 26: 29-43

5 Yuan J N, Wang D X, Wang Q L, et al. A 28-year climatological analysis of size parameters for northwestern Pacific tropical cyclones. Adv Atmos Sci, 2007, 24: 24-34

6 Chen T C, Weng S P. Interannual variation in the tropical cyclone formation over the western North Pacific. Mon Weather Rev, 1998, 126: $1080-1090$

7 Chan J C L. Tropical cyclone activity in the northwest Pacific in relation to the stratospheric quasi-biennial oscillation. Mon Weather Rev, 1995, 123: 2567-2571

8 Liebmann B, Hendon H H, Glick J D. The relationship between tropical cyclones of the western Pacific and Indian Oceans and the Madden-Julian oscillation. J Meteorol Soc Jpn, 1994, 72: 401-411

9 Zhu C W, Nakazawa T, Li J P. Modulation of tropical depression/ cyclone over the Indian-western Pacific oceans by Madden-Julian Oscillation (in Chinese). Acta Meteorol Sin, 2004, 62: 42-51

10 Dickinson M, Molinari J. Mixed Rossby-gravity waves and western Pacific tropical cyclogenesis. Part I: Synoptic evolution. J Atmos Sci, 2002, 59: 2183-2196

11 Wang H J, Fan K. Relationship between the Antarctic oscillation and the western North Pacific typhoon frequency. Chinese Sci Bull, 2007, 52: $561-565$

12 Wang H J, Sun J Q, Fan K. Relationships between the North Pacific Oscillation and the typhoon/hurricane frequencies. Sci China Ser D-Earth Sci, 2007, 50: 1409-1416

13 Zhou B T, Cui X, Zhao P. Relationship between the Asian-Pacific oscillation and the tropical cyclone frequency in the western North Pacific. Sci China Ser D-Earth Sci, 2008, 51: 380-385

14 Cui X, Zhou B T, Fan K. Linkage between Asian-Pacific oscillation and the large-scale atmospheric circulations related to the tropical cyclone frequency over the western North Pacific in Bergen climate model (in Chinese). Clim Environ Res, 2010, 15: 120-128

15 Li C Y. El Nino and typhoon action over the western Pacific. Chinese Sci Bull, 1986, 31: 538-542

16 He M, Song W L, Chen X F. Typhoon activity in the northwest Pacific in relation to El Nino/La Nina events (in Chinese). J Tropic Meteorol, 1999, 15: 17-25

17 Chan J C L. Tropical cyclone activity in the Northwest Pacific in relation to the El Niño/Southern Oscillation phenomenon. Mon Weather Rev, 1985, 113: 599-606

18 Lander M A. An exploratory analysis of the relationship between tropical storm formation in the western North Pacific and ENSO. Mon Weather Rev, 1994, 122: 636-651

19 Chan J C L. Tropical cyclone activity over the western North Pacific associated with El Niño and La Niña events. J Clim, 2000, 13: 2960-2972

20 Wang B, Chan J C L. How strong ENSO events affect tropical storm activity over the western North Pacific. J Clim, 2002, 15: 1643-1658

21 Camargo S J, Sobel A H. Western North Pacific tropical cyclone intensity and ENSO. J Clim, 2005, 18: 2996-3006

22 Chen G H, Huang R H. The effect of warm pool thermal states on tropical cyclone in west Northwest Pacific (in Chinese). J Trop Meteorol, 2006, 22: 527-532

23 Chen G H, Huang R H. Influence of monsoon over the warm pool on interannual variation on tropical cyclone activity over the western North Pacific. Adv Atmos Sci, 2008, 25: 319-328

24 Zhou B T, Cui X. Hadley circulation signal in the tropical cyclone frequency over the western North Pacific. J Geophys Res, 2008, 113: D16107, doi:10.1029/2007JD009156

25 Zhou B T, Cui X. Modeling the influence of spring Hadley circulation on the summer tropical cyclone frequency in the western North Pacific (in Chinese). Chinese J Geophys, 2009, 52: 2958-2963

26 Chan J C L, Shi J E, Lam C M. Seasonal forecasting of tropical cyclone activity over the western North Pacific and the South China Sea. Weather Forecast, 1998, 13: 997-1004

27 Chan J C L, Shi J E, Liu K S. Improvements in the seasonal forecasting of tropical cyclone activity over the western North Pacific. Weather Forecast, 2001, 16: 491-498

28 Fan K. North Pacific sea ice cover, a predictor for the western North Pacific typhoon frequency? Sci China Ser D-Earth Sci, 2007, 50: 1251-1257

29 Fan K. New predictors and a new prediction model for the typhoon frequency over western North Pacific. Sci China Ser D-Earth Sci, 2007, 50: 1417-1423

30 Fan K, Wang H J. A new approach to forecasting typhoon frequency over the western North Pacific. Weather Forcast, 2009, 24: 974-986

31 He S X, Zhang B Y, Fu X Q. Relationship between the frequency of midsummer typhoon over Northwest Pacific and the condition of large scale circulation (in Chinese). J Trop Meteorol, 1986, 2: 251256

$32 \mathrm{Li} \mathrm{Z} \mathrm{Z}$. Preliminary statistical analysis on the relationship between the cross-equatorial flow and the Chinese weather (in Chinese). Meteorol Month, 1986, 4: 11-14

33 Sun S Q, Liu G, Zhang Q Y. The influence of the circulation anomalies in the southern hemisphere on the tropical cyclone frequency in summer over the western Pacific and its mechanism (in Chinese). Chin J Atmos Sci, 2007, 31: 1189-1200

34 Kalnay E, Kanamistu M, Kistler R, et al. NCEP/NCAR 40-year reanalysis project. Bull Am Meteorol Soc, 1996, 77: 437-471

35 Smith T M, Reynolds R W. Improved extended reconstruction of SST (1854-1997). J Clim, 2004, 17: 2466-2477

36 Landsea C W, Anderson C, Charles N, et al. The Atlantic hurricane database re-analysis project: Documentation for the 1851-1910 alterations and additions to the HURDAT database. In: Murname R J, Liu K B, eds. Hurricanes and Typhoons: Past, Present and Future. New York: Columbia University Press, 2004. 177-221

37 Shi X H, Xu X D. Regional characteristics of the interdecadal turning of winter/summer climate modes in Chinese mainland. Chinese Sci Bull, 2007, 52: 101-112

38 Wu B Y, Zhang R H. Interdecadal shift in the western North Pacific summer SST anomaly in the late 1980s. Chinese Sci Bull, 2007, 52; 2559-2564

39 Zhang R H, Wu B Y, Zhao P, et al. The decadal shift of the summer climate in the late 1980s over East China and its possible causes (in Chinese). Acta Meteorol Sin, 2008, 66: 697-706

40 Wang X, Wang D X, Zhou W. Decadal variability of twentieth-century El Niño and La Niña occurrence from observations and IPCC AR4 coupled models. Geophys Res Lett, 2009, 36: L11701, doi: 10.1029/2009GL037929

41 Huang J Y. Statistic Analysis and Forecast Methods in Meteorology (in Chinese). Beijing: Meteorology Press, 2000. 29-38

42 Lang X M, Wang H J. Can the climate background of western North Pacific typhoon activity be predicted by climate model? Chinese Sci Bull, 2008, 53: 2392-2399

43 Elsberry R L, Jeffries R A. Vertical wind shear influences on tropical cyclone formation and intensification during TCM-92 and TCM-93. Mon Weather Rev, 1996, 124: 1374-1387

44 Wang H J. Preliminary research on the inner-atmosphere-originated seasonal climate predictability (in Chinese). Chin J Atmos Sci, 2005, 29: $64-70$

Open Access This article is distributed under the terms of the Creative Commons Attribution License which permits any use, distribution, and reproduction in any medium, provided the original author(s) and source are credited. 